\title{
Environmental, Social and Governance Key Performance Indicators from a Capital Market Perspective
}

\author{
AleXander BASSEN ANd ANA MARIA KovÁcs*
}

\section{Ökologische, soziale und Corporate Governance Leistungsindikatoren aus Kapitalmarktperspektive}

Environmental, social and governance factors are becoming increasingly significant for comprehensive firm valuation. These factors are however of a qualitative nature and therefore difficult to express in numerical figures. Consequently, disclosure and the relevancy thereof to investors are problematic. The article analyses a breakthrough instrument which facilitates the quantification and representation of such data against the background of international institutional efforts aiming to promote standardised qualitative reporting for extra-financial information.

Keywords: Capital Markets, ESG Information, Reporting, Key Performance Indicators

\section{Relevance of extra-financial information}

There is more to corporate performance than what traditional financial reporting can illustrate. The increasing breach between financial reporting and firm value results from the declining ability of accounting and financial reporting data to represent and report information that is useful in assessing firm value and management performance (Yen 2004: 1). The shift of western countries to information and service economies has drastically reduced the importance of tangible assets within enterprises. Accordingly, intangibles increasingly account for a significant proportion of the value of a company, especially over the longer term. A recent global survey indicates that these make up to $66 \%$ of the market value of globally listed companies (Brand Finance 2007: 5). "The problem with intangible assets [however] is that traditional accounting methods fail to capture their value" (Kossovsky 2007). Indeed, corporate financial statements lack the capacity to inform management and investors about the value of reputation, quality, brand equity, safety, workplace culture, strategies, know-how and a host of other assets that are more significant than ever in a knowledge-based global economy. A single glance at almost double market-to-book ratios of S\&P 500 gives emphasis to the current debate on "unaccountable accounting".

Prof. Dr. Alexander Bassen, Fakultät Wirtschafts- und Sozialwissenschaften, Universität Hamburg, Rentzelstr. 7, D-20146 Hamburg, Tel.: +49-(0)40-42838-4064, Fax: +49-(0)40-42838-6272, E-Mail: alexander.bassen@wiso.uni-hamburg.de, Forschungsschwerpunkte: Investor Relations, Environmental, Social and Governance Issues.

Ana Maria Kovács, MA, Fakultät Wirtschafts- und Sozialwissenschaften, Universität Hamburg, Rentzelstr. 7, D-20146 Hamburg, Tel.: +49-(0)40-42838-6467, Fax: +49-(0)40-42838-6272, E-Mail: ana.kovacs@wiso.uni-hamburg.de, Forschungsschwerpunkte: Corporate Responsibility, Sustainability \& Reporting. 
Furthermore, intangibles do not always necessarily constitute assets; they may also represent a liability to a business if poorly managed. ${ }^{1}$ Similarly, extra-financials are not of explicit financial nature but have direct as well as indirect financial consequences for an enterprise and its investors. These extra-financial ${ }^{2}$ factors are not necessarily a direct source of future benefits as intangibles are, but rather constitute the foundation for upholding present and future business' viability and determine corporate performance over the long run.

The efficient market theory states that share prices reflect all known information relating to a share. All new information has the potential to impact the fundamental valuation of equity. The more complete and reliable the information available, the more accurate is the valuation of the future performance of the respective security. Even if extra-financial information may not necessarily affect the price of a company's share during normal operations, in cases where reputational or monetarily quantifiable litigation risk exists, investment professionals turn much attention to the respective information.

That is why companies make an increasing effort to provide investors with disclosures on extra-financial aspects which capture additional dimensions of corporate performance that are not accounted for within financial data. The multitude of corporate social responsibility, environmental, sustainability and corporate governance reports currently issued by listed companies depicts information on these factors. However, despite an effective information overflow, this is not organised in such a manner as to become relevant for investment professionals. Disclosures are complex and sometimes hard to understand and implement even for sophisticated users. One of the key features of extra-financial aspects is that they are often specific to each particular company's operations. Hence, disclosures thereof vary from company to company, resulting in inconsistent representation across companies. Additionally, enterprises use different labels and definitions for their disclosures of extra-financial aspects, hampering comparability. Furthermore, as these are commonly not quantified and especially non-monetised, it is difficult to translate their performance to the proper magnitude of effect in financial terms, i.e. into judgements of future financial performance (Yen 2004: 15).

1 Intangibles may either be "non-physical sources of expected benefits" (Zambon et al. 2003: 17) i.e. intangible assets or intangible liabilities if they constitute a source of losses. They range from strategies to processes, to abstract elements such as innovation, transparency, etc. Academic literature has not yet delivered a comprehensive definition. This would have allowed delimitation from the somewhat overlapping notion of extra-financials. Extra-financials may be understood as qualitative factors describing outcomes of corporate structures, strategies and processes which in turn have material impacts on corporate performance. To reduce complexity, intangibles and extra-financials will be used interchangeably within the present article.

2 Within this paper, the term extra-financial is preferred to the more widespread terminology of non-financial information. This choice of terms is intended to reflect the materiality, i.e. financial implications of these additional aspects influencing corporate performance and delimiting them from other, non-material information falling under the non-financial umbrella. 


\section{Environmental, social and governance issues - ESG}

One particular set of extra-financials has been experiencing soaring scrutiny within the last years, namely aspects related to environmental, social and governance (ESG) issues. Although the terminology is employed in various contexts - risk valuation, socially responsible investment, corporate responsibility, etc. - up to present there is no clear general understanding of this concept. The term appears in the United Nations Principles of Responsible Investment and is also employed by major business consulting firms. Yet business and academic literature lag behind a definitional attempt.

The concept of ESG issues refers to extra-financial material information about the challenges and performance of a company on these matters. It thus delivers additional relevant information, allowing more differentiated investment judgements by enabling investors to better assess risks and opportunities.

Despite academic and business professionals' efforts, there has yet been no conclusive evidence which could universally either confirm or refute a direct causal link between good environmental, social or governance performance and a firm's financial performance ${ }^{3}$. It is however evident that evaluation of ESG matters enables a thorough understanding of the risks and opportunities a company faces, allowing enhanced security selection and risk management. Furthermore, ESG performance may serve "as a proxy for management quality, in so far as it reflects the company's ability to respond to long term trends and maintain competitive advantage" (Ling et al. 2007, cited in UNEP 2007: 44). Additionally, ESG analysis leads to improved understanding of how future trends could affect a certain industry or the entire economic landscape for that matter. Financial professionals for instance anticipate that ESG issues and climate change in particular will "gradually but powerfully change the economic landscape" in which companies operate and "cause periodic sharp movements in asset prices" (Llewellyn 2007: 1). Thus, while of fundamental relevance within socially responsible investment (SRI) strategies, ESG measures actually bare significant importance for mainstream business valuation and investment decision-making, especially in the context of long-term performance and risk evaluation (Derwall 2007).

Companies face varying degrees of ESG-based risk exposures depending on the industry and region in which they operate (CFA Institute 2008: 2). And while certain ESG aspects benefit regular attention from investment analysts, others are increasingly gaining momentum. For instance, financial analysts consider corporate governance issues to constitute a classic examination area within corporate valuation, whereas issues such as social or environmental impact experience incremental consideration (ECCE 2007a: 9). This situation could be attributed to the historically determined higher regulatory agenda regarding corporate governance matters (and the ensuing improved traceability of such issues through according data compilation specifications, requirements and disclosures) as opposed to the more recently acknowledged impact of social and environmental aspects by investment professionals.

The importance of the latter, however, is ever more evident and the fundamental implications of these relative 'newcomers' to extra-financial analysis - social and 
environmental considerations - explain why financial analysts predict an increase in the breadth and depth of scrutiny placed on them (ECCE 2007a). Recent safety issues at Mattel and media scandals relating to child labour in the supply chains of important apparel retailers offer illustrative evidence of how such factors affect a company's reputation and revenues. In the environmental arena, indications of massive pending legislative and regulatory framework transformations due to climate change also constitute factors increasingly gaining investor's attention and desideratum to integrate into corporate valuation.

Climate change as one of the most prominent environmental issues facing companies has a particular relevance for financial markets. It is foreseeable that companies will have to operate under different conditions in the near future: where carbon-based energy sources may either face restricted use, increased taxation, and possibly increased regulation (Bassen 2007). The magnitude of pending carbon regulation and consequent shifting cost structures is still uncertain but clearly foreseeable. One can tell that carbon-intensive industries, such as oil, gas and the utilities sector will be massively impacted, with further climate change regulations affecting all sectors, including those outside these specific industries. Some companies also acknowledge the wider implications of carbon emissions, for instance that "changing and less predictable weather patterns potentially could affect consumer buying patterns, production locations, product shipping and even the cost of insurance coverage to facilities" (Nike 2005: 67). Thus, those which seize an early opportunity to develop technologies in anticipation of such new environment may offer a lower risk profile and enhanced return opportunities to their shareholders compared with competitors that do not adequately prepare for these developments (CFA Institute 2008: 4). To assess potential future effects of such changes and the risks these bare in particular for carbon-dependent businesses, access to appropriate disclosures and metrics that allow meaningful comparisons between companies in the same industries or with similar risk profiles is essential.

The problems related to the provision of ESG information however are numerous. As ESG issues are inherently of extra-financial nature, they bear the intrinsic shortcomings common to all extra-financial information. Above all, they lack consistent and standardised definitions and disclosure. Moreover, corporate reports on ESG matters are of limited use to investment professionals, as relevant information is typically communicated at irregular intervals, in prose style and scattered between on-line resources and printed reports. Therefore, even when quantified, information is difficult to compare with data delivered by peers or across periods. Furthermore, analysts and investors consider that companies do not provide enough information to allow effective assessment of these factors' impacts, although in a European study $73 \%$ of the respondent companies indicated they had developed a policy for including and 91\% actually include ESG issues in financial communication (ECCE 2007b: 5). The same report illustrates that there are significant differences across countries concerning the way this information is presented. 


\section{Steps towards holistic capital market-relevant reporting}

Efforts to improve ESG reporting are to be seen against the wider background of initiatives aimed at enhanced extra-financial corporate reporting. Numerous locally and globally significant initiatives seek to promote holistic corporate reporting with standardised, comparable information platforms for the use of investors. The approaches come from diverse players (regulators, policy makers, standard-setters, professional associations, etc.) and are fragmented. Some initiatives offer general guidance and recommendations on how to adequately recognise, measure and disclose extra-financials. Others only focus on selected issues (e.g., see for sustainability matters ${ }^{4}$ or climate change Bassen 2007), while again others provide complete reporting frameworks.

\subsection{Extra-financial performance indicators}

Although the field doesn't lend itself to precise metrics, extra-financial performance measures or indicators may be drawn up for certain items and these represent the potentially most standardisable and comparable extra-financial items. Unlike qualitative information, performance indicators, especially if reduced to key figures, have the advantage that given their numeric character they offer a fast, condensed overview over a businesses' actual performance on extra-financial matters.

Indicators have three basic functions: control, communication and improvement (Franceschini et al. 2007: 10). Managers and employees of a company can measure and therefore control the resources under their responsibility with the help of indicators. Furthermore, indicators communicate performance to internal staff and management as well as external stakeholders. Finally, they enable performance improvement as they identify the differences between the actual and target state. That is why, as part of current efforts to promote management and reporting on intangibles, most initiatives support the development of key performance indicators for extra-financial information.

\subsection{International efforts for holistic reporting}

The most comprehensive initiative is the newly founded World Intellectual Capital Initiative (WICI). Encompassing notorious bodies as the OECD, the Enhanced Business Reporting Consortium (EBRC) and the EFFAS Commission on Intellectual Capital (EFFAS CIC) among others ${ }^{5}$, the WICI held its first meeting in October 2007.

$4 \quad$ For instance, the United Nation's Global Reporting Initiative (GRI) should be mentioned as the most prominent reporting standard for sustainability issues. The GRI G3 reporting framework and performance indicators have created a first step towards standardised disclosure on sustainability factors. However, they address a wide range of corporate stakeholders and the vast number of indicators and their accompanying compiling protocols make them difficult to incorporate into capital markets processes, e.g. use in calculations and relate to monetary figures. Consequently, the authors focus solely on initiatives specifically targeting ameliorated reporting from a capital market perspective.

5 The WICI is comprised of the following: Japanese METI (Ministry of Economy, Trade \& Industry), US Enhanced Business Reporting Consortium (EBRC), Waseda University and University of Ferrara, European Financial Analysts, Commission on Intellectual Capital, OECD, European Commission (observer), European Investment Bank (EIB), World Intellectual Property Organisation (WIPO) (observer), Brazilian Development Bank (BNDES), Society for Knowledge Economics in Australia (SKE). 
The aim of this initiative is to work towards a generally accepted framework for reporting intangibles worldwide.

In its proceedings towards this ambitious goal, the WICI can rely on previous input from various actors on the multiple constituents of such a framework (reporting frameworks, guidelines, indicators, etc.). One of them is the EBRC, which has already produced a framework for holistic corporate reporting - the current 'EBRC Framework Version 2.1'. This reporting framework incorporates discussions on business landscape, strategy, resources and processes as well as extra-financial performance measures. ${ }^{6}$

Others are the Japanese Ministry of Economy, Trade and Industry (METI) and the European Federation of Financial Analysts' Societies Commission on Intellectual Capital (EFFAS CIC). The Japanese (METI) 'Guidelines for Disclosure of Intellectual Assets Based Management' contemplate past-present-future relationships and offer thirty-eight specific indicators including a wide range of value drivers, performance measures, and intangibles. ${ }^{7}$ The EFFAS CIC has recently released the 'Principles for Effective Communication of Intellectual Capital', providing guidance for drawing up and disclosure of sector-specific indicators for extra-financial topics. ${ }^{8}$

As for national regulators, the U.S. Securities and Exchange Commission's "Advisory Committee on Improvements to Financial Reporting" 2008 draft report also encourages the private sector to develop "key performance indicators (KPIs) (...) that would capture important aspects of a company's activities that may not be fully reflected in its financial statements or may be non-financial measures", as such KPIs are "to provide investors with an enhanced understanding of company performance" (SEC 2008: 4).

\subsection{Environmental, social and governance performance indicators}

Narrowing the extra-financial discussion down to ESG matters, amazing progress is to be noted, with various schemes already having taken effect.

Thus, the EU Accounts Modernisation Directive, which became effective on January $1^{\text {st }} 2005$, introduced requirements for companies in the EU to include in their Directors' Report "both financial and, where appropriate, non-financial key performance indicators relevant to the particular business, including information relating to environmental and employee matters" to enable a balanced and comprehensive analysis of the development and performance of the business (Directive 2003/51/EC).9 However, no comprehensive framework for environmental, social and governance reporting and key performance indicators existed until recently, when the German Society of

\footnotetext{
$6 \quad$ For details visit: www.ebr360.org.

7 For details visit: www.meti.go.jp/policy/intellectual_assets/english.html.

$8 \quad$ For more details visit: www.effas.com.

9 Following this requirement, the UK Government for instance provided companies support by publishing the "Environmental Key Performance Indicators Reporting Guidelines for UK Business" in 2006, giving guidance on how to report on environmental performance using determined performance indicators. For details visit: www.defra.gov.uk.
} 
Investment Professionals (DVFA) issued a standard through its Committee on ExtraFinancials. ${ }^{10}$

The aim of the new standard is to deliver a consistent and comprehensive framework for ESG reporting within financial analysis of corporate performance. Hence 12 general (applying to all sectors and industries) and 18 preliminary sector-specific KPIs were defined. In addition to the environmental, social and governance indicators, KPIs depicting the concept of long-term viability were developed, as representation of a company's ability to produce long-term profits without sacrificing assets, skills, or resources by means of short-term exploitation. Along with these KPIs, the DVFA defined basic principles for extra-financial reporting.

An important aspect is that despite the clear dedication towards investment professionals and a clear differentiation from existing indicators or reporting frameworks, the DVFA released its KPIs in such a manner that they do not conflict with existing reporting schemes, but rather to be compatible with traditional reporting statements and formats, tying seamlessly into existing initiatives' efforts. What is more, formal endorsement from the EFFAS' Management Committee is likely to bolster the European significance of the new standard.

The methodology by which the ESG KPIs were developed by the DVFA emanated from the very same ESG-related problems detailed previously. Therefore, the intention was to identify KPIs that would

- depict a correlation to risk or success factors of corporate business,

- be significant and relevant for investment decisions,

- be firmly anchored in corporate management systems,

- quantified, comparable and benchmarkable from peer to peer,

- depict dynamics (i.e. between reporting periods),

- manageable in dimension,

- and true to the designation of "key" indicators (DVFA 2008: 7).

The commission in charge of developing these indicators set out by researching corporate reports on ESG data and gathering material on KPIs already in use or reported by corporates. Thus, 30 KPIs were pre-selected from an initial 600-item long list through deductive iterative processes, moderating the discussion between mainstream investors, financial analysts and corporate representatives. Subsequently, the draft KPIs were surveyed and confirmed for relevance and validity with international investment professionals within a survey covering 122 mainstream sell- and buy-side investment professionals (see DVFA 2007 and 2008). professionals, financial analysts, corporates, auditing professionals and experts in the field of ESG issues. 


\begin{tabular}{|c|c|c|c|c|c|c|c|c|}
\hline & \multicolumn{2}{|r|}{$\mathrm{E}$} & \multicolumn{2}{|r|}{$\mathrm{S}$} & \multicolumn{2}{|r|}{ G } & \multicolumn{2}{|r|}{$\mathrm{V}$} \\
\hline & & Environmental & & Social & & Governance & & Long-term Viability \\
\hline $\begin{array}{l}\text { Sector-specific } \\
\text { KPIs } \\
\text { which apply to } \\
\text { certain sectors }\end{array}$ & $\begin{array}{l}\text { E3 } \\
\text { E4 } \\
\text { E5 } \\
\text { E6 } \\
\text { E7 }\end{array}$ & $\begin{array}{l}\mathrm{CO}_{2} \text { Emissions } \\
\mathrm{NO} \text {, SO Emissions } \\
\text { Waste } \\
\text { Environmental } \\
\text { Compatibility } \\
\text { End-of-Lifecycle Impact }\end{array}$ & $\begin{array}{l}\text { S6 } \\
\text { S7 } \\
\text { S8 } \\
\text { S9 } \\
\text { S1 } \\
\text { S1 } \\
\text { S1 }\end{array}$ & $\begin{array}{l}\text { Diversity } \\
\% \text { of Credit Loans, } \\
\text { Undergone ESG Screening } \\
\% \text { of Funds Managed in } \\
\text { Accordance to ESG Criteria } \\
\text { Financial Instruments held in } \\
\text { Accordance to ESG Criteria } \\
\text { Investments in Accordance } \\
\text { with ESG } \\
\text { Supplier Agreements in } \\
\text { Accordance with ESG } \\
\text { Health \& Safety of Products }\end{array}$ & $\begin{array}{l}\text { G4 } \\
\text { G5 }\end{array}$ & $\begin{array}{l}\text { Litigation } \\
\text { Payments } \\
\text { Dimension of } \\
\text { Pending Legal } \\
\text { Proceedings }\end{array}$ & $\begin{array}{l}\text { V3 } \\
\text { V4 } \\
\text { V5 } \\
\text { V6 }\end{array}$ & $\begin{array}{l}\text { R\&D Expenses } \\
\text { Number of Patents } \\
\text { Investments in } \\
\text { Research on } \\
\text { New Risk } \\
\text { Customer Retention }\end{array}$ \\
\hline
\end{tabular}

Figure 1: DVFA Key Performance Indicators (DVFA 2008: 3)

The KPIs are further broken down into 'Master' and 'Applied' KPIs. The Master KPIs (to be seen in Fig. 1) thus describe the general purpose of the issues to be reported and are not the actual items to be reported. It is Applied KPIs behind each Master KPI that describe the line items to be reported. ${ }^{11}$

For instance, the Master KPI E2-Deployment of Renewable Energy may be described by the Applied KPIs

- E2-1 \% of energy in kwh from renewable energy sources as of total energy consumed

- E2-2\% of energy in kwh from combined heat and power generation as of total energy consumed

Reporting companies may select between the provided Applied KPIs depending on the applicability to their respective business model and industry. Taxonomies, KPI calculation methods and short names serving for XBRL-based reporting templates as well as industry-specific indications of KPI applicability are also provided.

Certainly, for such ESG data to be reported certain basic prerequisites are indispensable. Individual companies need to actually have a strategy related to ESG issues. Additionally, they need to have an ESG management system in place which can ensure operational implementation and performance measurement. In its guidelines, the DVFA doesn't neglect to present sensible recommendations concerning the setup and communication thereof.

A major strength of the presented indicators and accompanying principles is that in their selection methodology, the DVFA considered a critical success factor: that the

$11 \quad$ For a thorough representation see DVFA 2008.

zfwu 9/2 (2008), 182-192 
environmental, social, governance and viability KPIs be acceptable and respected by mainstream financial analysts and investors. If we link this aspect to the fact that companies already partially use some of the presented KPIs in their extra-financial reporting - however in a heterogeneous manner - it is to anticipate that the framework provided by the DVFA will generously serve the business community in delivering qualitative information in a generally accepted manner. This in turn benefits financial investment professionals as they can make better grounded decisions easier.

Another typical feature of the KPIs developed by the DVFA is that they leave open room for corporates to set benchmarks: for instance, it is recommended that firms not only disclose their own performance, but put this into context by additionally presenting relational benchmarks (external references such as industry-related averages, data from peers, etc.) to the reported line items. This, however, raises questions concerning the procurement of the respective information. Where and how is such information to be obtained? Furthermore, does such effort also entail spending extra-resources?

Additionally, recommendations encouraging businesses to selectively disclose on those Applied KPIs which suit them best points to an adaptable approach. At the same time this raises doubts concerning corporate readiness for disclosure on sensitive matters given the handy option to simply avoid suchlike. Practically, this may hamper rigorous comparability, as companies are allowed to report different parameters under the same Master KPI. Such wide discretion then again bares an essential benefit considering the voluntary character of the DVFA framework as typically excessively restrictive requirements bring prejudice on a voluntary initiatives' wide adoption.

\section{Outlook}

Investment professionals' increased desideratum to integrate extra-financial information into firm valuation is experiencing important dynamics. The indicators developed by the DVFA represent a valuable contribution as they aid mainstream investment professionals to perform enhanced firm assessments and quantify risks and opportunities related to environmental, social, governance and long-term viability matters.

The primary beneficiary of an anticipated proliferation of ESG KPIs however is the socially responsible investment (SRI) community. Although ESG issues play a particular role within SRI strategies, the current methods for gathering, evaluation and especially comparison of SRI-relevant, i.e. ESG information, is laborious and costly due to the reasons already illustrated in this article. The existence of standardised qualitative disclosure on these matters will bare great advantage by reducing the costs of information acquisition and processing, making such strategies accessible to a broader investment community.

ESG KPIs also constitute an important contribution in the context of international reporting convergence efforts. Larger initiatives such as the WICI can resort to these for sound performance metrics in the area of environmental, social, governance and also long-term viability matters. Considering the current trend towards enhanced scrutiny on ESG issues and the penury of truly practicable solutions it may be expected that the proposed standard will swiftly gain momentum. A strong argument is also represented by the fact that through its inherent nature, the DVFA model has 
cleared from the outset the typical range of hurdles voluntary reporting standards usually face. The standard was developed by investment professionals, i.e. the target audience for corporate disclosures par excellence. Since it bases on already implemented metrics, acceptance will certainly not represent a concern.

Concerning the larger debate over performance indicators in the field of extrafinancials, a cautionary note is however to be made: not everything that counts can be measured and not everything that can be measured counts. While baring significant advantages for an investment community overwhelmed with information, concentrating purely on numbers might divert attention from actual issues, especially if they have an obscure character. Also, managing and keeping track of KPIs is a laborious task but is not an end in itself. Information only becomes useful when it reveals something to its receptor and must therefore always be seen in perspective in order to permit tactical judgment and recognise less obvious risks. ESG KPIs do have the ability to depict certain factors relevant for assessing risks. Their mere calculation however doesn't replace a comprehensive assessment of risks and opportunities.

Finally, further academic research is needed to document the causal link between environmental, social and governance issues and corporate financial performance. This will be one of the most crucial factors determining the use and proliferation of ESG information and metrics.

\section{References}

Bassen, A. (2007): Carbon Disclosure Project - Germany Report 2007, BVI Bundesverband Investment und Asset Management e. V., Frankfurt a. M.

Brand Finance (2007): Global Intangible Tracker: An annual review of the world's intangible value, available online at: http://www.brandfinance.com/Uploads/pdfs/BF_GIT_07_ REPORT_Final\%20Version\%20Low\%20Res.pdf.

CFA Institute (2008): Environmental, Social, and Governance Factors at Listed Companies: A Manual for Investors, edited by the CFA Centre for Financial Market Integrity, available online at: www.cfainstitute.org/centre/topics/esg/.

Derwall, J. (2007): The Economic Virtues of SRI and CSR, Doctoral Dissertation, Erasmus Research Institute of Management, Erasmus University Rotterdam, available online at: publishing.eur.nl/ir/repub/asset/8986/ESP2007101F\&A9058921328DERWALL.pdf.

ECCE - European Centre for Corporate Engagement (2007a): Use of Extra-Financial Information by Research Analysts and Investment Managers, available online at: http://www. corporate-engagement.com/download.php?publicationID $=197720$.

ECCE - European Centre for Corporate Engagement (2007b): Extra-Financial Information in Financial Communication of European Companies, available online at: http://www. corporate-engagement.com/index.php?pageID=1881\&n=327\&itemID =246504.

Franceschini, F./ Galetto, M./ Maisano, D. (2007): Management by Measurement - Designing Key Indicators and Performance Measurement Systems, Heidelberg/Berlin: Springer Verlag.

Kossovsky, N. (2007): Executive Secretary IAFS, on the occasion of the Intangible Asset Finance Society Holding (IAFS) Conference on Impact of Extra-Financial Information 14.12.2007 in NYC, available online at: http://findarticles.com/p/articles/mi_m0EIN /is_2007_Dec_4/ai_n27463019. 
Ling, A./ Forrest, S./ Lynch, M./ Fox, M. (2007): Global Food \& Beverages: Integrating ESG, Goldman Sachs.

Llewellyn, J. (2007): The Business of Climate Change: Challenges and Opportunities, Lehman Brothers, available online at: http://www.lehmantrust.biz/who/intellectual_capital/pdf /business_of_climate_change_i.pdf.

Nike (2005): Corporate Responsibility Report FY2004, available online at: http://www. nikeresponsibility.com/pdfs/color/Nike_FY04_CR_report.pdf.

UNEP - United Nations Environment Programme Finance Initiative \& Mercer (2007) (Eds.): Demystifying Responsible Investment Performance. A Review of Key Academic and Broker Research on ESG Factors, available online at: www.calvert.com/pdf/demystifying responsible_investment_performance.pdf.

Yen, A. C-C. (2004): Effects on Investor Judgements from Expanded Disclosures of Nonfinancial Intangibles Information, Doctoral Dissertation, University of Texas-Austin, available online at: http://hdl.handle.net/2152/1150.

Zambon, S./ Abernethy, M./ Wyatt, A./ Bianchi, P./ Labory, S./ Del Bello, A./ Lev, B. (2003): Study on the Measurement of Intangible Assets and Associated Reporting Practices. Commission of the European Communities, Enterprise Directorate General, April 2003, available online at: ec.europa.eu/enterprise/services/business_related_services/ policy_papers_brs/intangiblesstudy.pdf.

\section{Extra-Financial Reporting Standards and Recommendations}

DVFA - Society of Investment Professionals in Germany (2007): Key Performance Indicators (KPIs) for Extra-/Non-Financial Reporting. Draft Version dated October 2007, DVFA Financial Papers No. 8/07_e, DVFA, Dreieich.

DVFA - Society of Investment Professionals in Germany (2008): KPIs for ESG. Key Performance Indicators for Environmental, Social and Governance Issues. A Guideline for Corporates on How to Report on ESG and a Benchmark for Investment Professionals on How to Integrate ESG into Financial Analysis, DVFA Financial Papers No. 8/08_e, DVFA, Dreieich.

EFFAS-CIC - European Federation of Financial Analysts' Societies-Commission on Intellectual Capital (2008): Principles for Effective Communication of Intellectual Capital, available online at: http://www.effas.com/pdf/EFFAS_CIC_web.pdf.

METI - Japan Ministry of Economy, Trade and Industry (2005): Guidelines for Disclosure of Intellectual Assets Based Management, available online at: http://www.meti.go.jp/ policy/intellectual_assets/GuidelineforIAM.pdf.

Official Journal of the European Union (2003): Directive 2003/51/EC - of the European Parliament and of the Council of 18 June 2003, available online at: http:/ / eur-lex.europa.eu/ LexUriServ/LexUriServ.do?uri=OJ:L:2003:178:0016:0022:EN:pdf.

SEC - U.S. Securities and Exchange Commission (2008): Draft Final Report of the Advisory Committee on Improvements to Financial Reporting to the United States Securities and Exchange Commission, 11. July 2008, available online at: http://www.sec.gov/about/ offices/oca/acifr/acifr-dfr-071108.pdf.

UK Government, Department for Environment, Food and Rural Affairs (2006): Environmental Key Performance Indicators Reporting Guidelines for UK Business, available online at: www.defra.gov.uk/environment/business/envrp/pdf/envkpi-guidelines.pdf.

Note: All internet resources have been accessible until the $6^{\text {th }}$ August 2008. 